\title{
A novel proposal of cooperation between a cage induction generator and the three-phase grid
}

\author{
Zbigniew Szular ${ }^{1}$ and Witold Mazgaj \\ Cracow University of Technology, Institute of Electromechanical Energy Conversion, Kraków, Poland
}

\begin{abstract}
In the paper, a new concept of the cooperation between a cage induction generator and the three-phase grid is presented. The induction generator is excited by a capacitor battery connected to the stator winding terminals. In order to ensure a stable operation, the battery capacity should be continuously adjusted. Three appropriate selected capacitors are connected to the stator winding terminals by means of two bi-directional controlled switches. The generator output voltage is stabilized by a suitable control of these switches. The stator winding terminals are also connected to the diode bridge rectifier. Energy in the DC bus is converted to the parameters of the three-phase grid $(400 \mathrm{~V}, 50 \mathrm{~Hz})$ by means of a three-phase voltage source inverter. Examples of numerical calculation results of the proposed energy generation system are presented in the end part of the paper.
\end{abstract}

\section{Introduction}

Two basic types of electrical generators are applied in wind plants and small water plants. Induction generators belong to the first group; the second one includes synchronous generators, first of all, the permanent magnet synchronous generators [1, 2]. Existing systems of energy generation should fulfil, among other, the following conditions [3]:

- generators can operate at a wide range of the turbine velocity; it refers especially to the wind turbines,

- energy generation systems should have a high efficiency of energy conversion,

- higher harmonics of the generator currents should be relatively low; otherwise a certain variable component of the generator torque occurs,

- energy generation system should be inexpensive, reliable and simple in operation.

Energy generation systems in wind and small water plants are often built on the basis of a squirrel cage induction generator (SCI generator) or a double fed induction generator (DFI generator). In the first systems, the SCI generators have been connected to the threephase grid directly or by means of a soft-starter (Fig. 1). The soft-starter has been used to reduce an inrush current which occurs during connection of the generator to the grid; usually the soft-starter is by-passed in normal operation conditions [4 - 9]. In this case the velocity of the SCI generators can vary within a narrow range; a generator slip is equal to $1-2 \%$. Due to this fact it is not possible to completely use wind energy or water stream energy in a wide range of the generator velocity changes. Mentioned drawbacks of the SCI generator operation do not occur when the generator is connected to the grid by means of a back-to-back converter

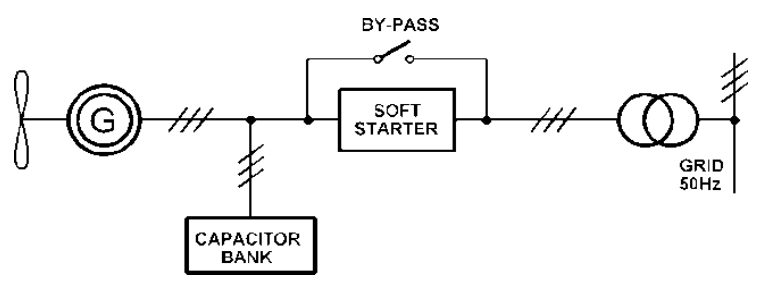

Figure 1. Energy generation system with the SCI generator directly connected to the three-phase grid.

(AC/DC/AC converter) $[1-4,8-15]$. This energy conversion system is shown in Figure 2. With the use of this system, the wind or the water stream energy can be converted to the grid in a wide range of the generator velocity. Reactive power which is necessary to produce a magnetic flux in the SCI generator is provided from a capacitor in the DC bus by means of a PWM rectifier. Vector control methods are usually implemented in these systems in order to keep the DC voltage at an assumed level $[11,13]$.

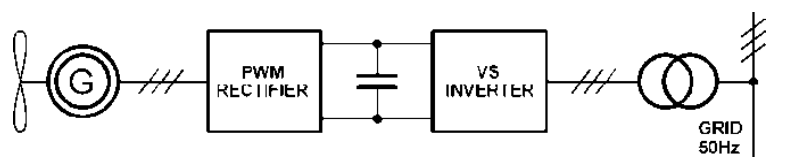

Figure 2. Energy generation system with the SCI generator connected to the three-phase grid by means of the back-to-back converter.

Quite frequently in energy generation systems the DFI generators are used. In this case the stator of the given DFI generator is directly connected to the three-phase grid, whereas the rotor is connected to this grid by means of the back-to-back converter $[1,4,6,8,9]$. In these systems the generator velocity can change in the range $\pm 30 \%$ with respect to the nominal velocity [1]

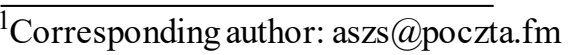


The presence of slip rings and brushes requires relatively frequent maintenance and it can cause failures in these generators.

The synchronous generators, especially generators excited by permanent magnets, are almost always connected to the three-phase grid via the back-to-back converters [2, 4, 9, 16-20]. These energy conversion systems can operate even at low wind or water stream speed.

\section{Topology of a novel energy generation system with the $\mathrm{SCl}$ generator}

Considering various energy generation systems, the squirrel cage induction generators seem to be an advantageous solution in wind and small water plants, because they have simple construction, low costs and low requirements for the operation and maintenance.
The complete use of the mentioned properties requires an application of the back-to-back converters. However, it results in significant complication of the control method of this converter. The advantageous properties of the SCI generators have encouraged us to develop a simpler energy generation system with the use of this generator.

It is worth underlining that a voltage source inverter (VS inverter) and an additional transformer has to be applied on the grid side because the content of higher harmonics in the current flowing from the VS inverter to the three-phase grid should be limited to the level specified by the relevant regulations. However, the requirements for the harmonic content in the generator currents are not critical. Therefore, instead of the PWM rectifier we propose to apply a simpler system whose topology is shown in Figure 3.

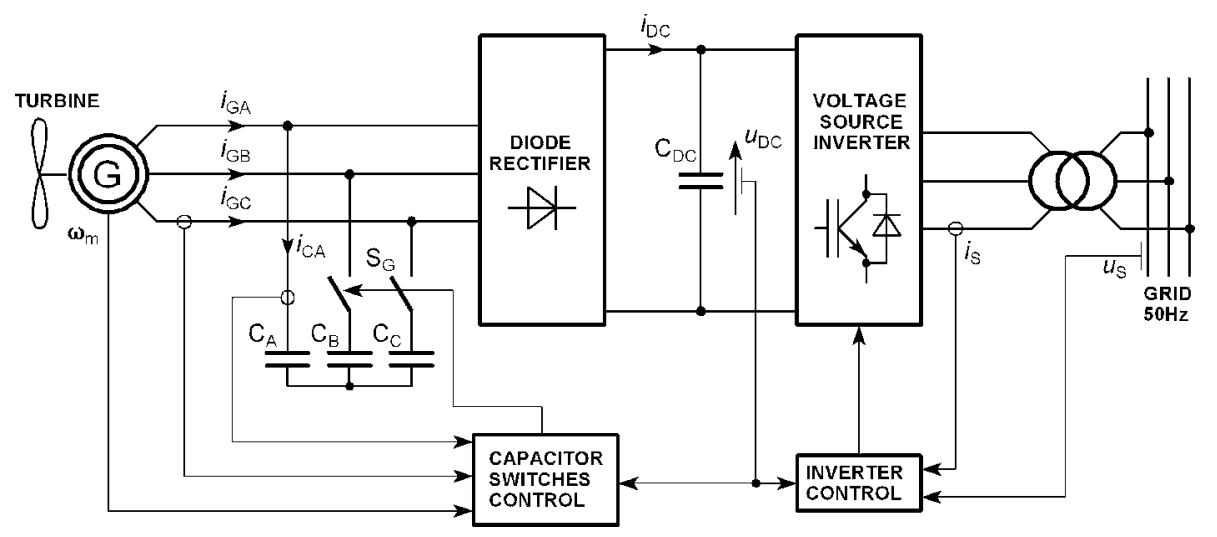

Figure 3. Topology of the proposed energy generation system: $\mathrm{G}-\mathrm{SCI}$ generator, $\mathrm{S}_{\mathrm{G}}$ - full-controlled bidirectional switches.

The stator terminals of the given SCI generator are connected to the diode bridge rectifier. Additionally, these terminals are connected to the three capacitors $\mathrm{C}_{\mathrm{A}}$, $\mathrm{C}_{\mathrm{B}}, \mathrm{C}_{\mathrm{C}}$ via two full-controlled bidirectional switches $\mathrm{S}_{\mathrm{G}}$; the capacitors are connected in a star configuration. These switches can be implemented as the two series connected Insulated Gate Bipolar Transistors or as only one transistor of this type which is included in the transverse branch of the Graetz rectifier. It is necessary to stress that both switches are turned on and turned off simultaneously by a common control signal. The diode rectifier is connected to the three-phase VS inverter which is coupled to the three-phase grid by means of a transformer, similarly as in existing energy conversion systems that use the back-to-back converter.

Some doubts may appear due to the occurrence of capacitors on both sides of the diode rectifier. However, during the normal operation of the proposed system, the voltage on the DC bus capacitor is higher than the resultant phase-to-phase voltage of the capacitor battery. Otherwise, a high current impulse could occur after the turn-on of the switches causing their damage. Due to the switching frequency of a few several $\mathrm{kHz}$, the diode rectifier should be constructed on the basis of fast diodes. Requirements for the VS inverter, cooperating with the three-phase grid, are the same as in existing systems of the energy conversion.

\section{Principles of the system operation and control strategy}

The basic assumption of the proposed system operation and control method is the possibility of the energy generation in a wide range of the wind or water stream speed. It was assumed that the generator velocity usually can vary from $50 \%$ to $150 \%$ with respect to its nominal angular velocity.

Conversion of the wind or water energy by the SCI generator has to be preceded by its self-excitation. Before beginning of this process the capacitors $C_{A}, C_{B}, C_{C}$ have to be pre-charged to the voltage of several dozen volts. This can be done using a simple electronic circuit and accumulator batteries, which should be installed in each energy generation system. During the self-excitation process the switches $\mathrm{S}_{\mathrm{G}}$ are still turned on. This process can take up to a few seconds, but this is insignificant in relation to the time period of the energy generation. The self-excitation depends not only on the initial voltage on the capacitor battery. The generator parameters and wind or water stream speed also influence this process significantly. The capacity of the battery capacitors is determined for the assumed minimum value of the generator angular velocity. It is known that the lower the generator velocity is, the higher should be the battery capacity. The required capacity is determined with taking into account the nonlinear magnetization characteristic of the SCI generator. It should be noted that the capacitor 
in the DC bus is charged to a voltage which results from the connection between the VS inverter and the threephase grid.

When the generator output voltage reaches the assumed value during the self-excitation process then the switches $\mathrm{S}_{\mathrm{G}}$ are turned off, and the capacitor battery is disconnected from the generator. From this moment the generator currents flow through diode rectifier to the DC bus and electrical energy is transferred from the SCI generator to the three-phase grid by means of the VS inverter (Fig. 4a). At the same time, the magnetizing current of the SCI generator begins to slowly decrease, thereby the generator magnetic flux and the voltage on its terminals also decrease. When the generator magnetic flux drops to the minimum value, which depends on the current generator velocity, then the switches $\mathrm{S}_{\mathrm{G}}$ are turned on again and the capacitor battery are connected to the generator terminals. Thus, the generator magnetic flux and the output voltage increase; at the same time the energy provided to the grid via the VS inverter causes a certain decreasing of the voltage on the capacitor $C_{D C}$ in the DC bus (Fig. 4b).

a)

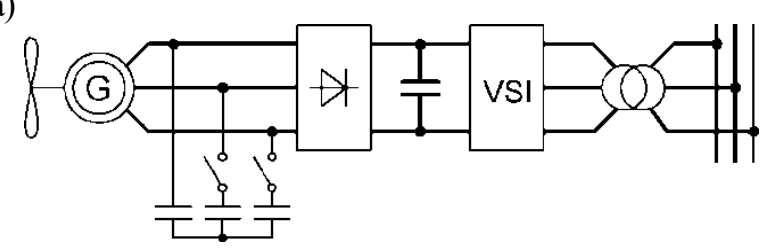

b)

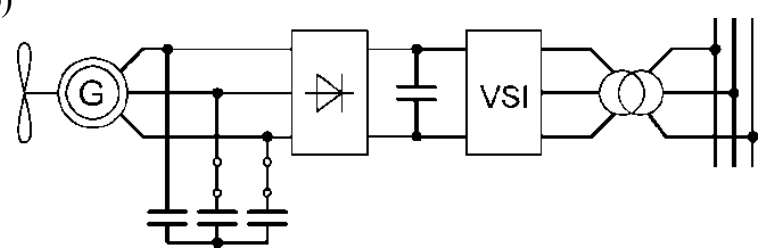

Figure 4. Simplified schematics of the proposed energy generation system: a) switches $\mathrm{S}_{\mathrm{G}}$ are turned on, b) switches $\mathrm{S}_{\mathrm{G}}$ are turned off.

In practice, the switching frequency is in the range from several hundred $\mathrm{Hz}$ to a dozen $\mathrm{kHz}$. Ensuring higher voltage of the capacitor $\mathrm{C}_{\mathrm{DC}}$ with respect to the highest voltage of the capacitor battery constitutes the basis for the system correct operation. In the time period when the switches $\mathrm{S}_{\mathrm{G}}$ are turned off, the voltages of the battery capacitors have a constant value. Due to inductances of the stator windings, the generator currents cannot change its value abruptly. Hence, these currents flowing to the diode rectifier are different from zero; almost always three diodes conduct, unlike the typical operation of such rectifiers. Due to the fact, that the sum of the battery currents is always equal to zero, the current flowing to the DC bus does not change its value during the switching process. It is worth underlining that the capacitor in the DC bus can be discharged by the input current of the VS inverter. As a result, the voltage in the DC bus can be lesser than the maximum voltage of the capacitor battery; it could lead to an unacceptable state of the system operation after the turn-on of the switches $\mathrm{S}_{\mathrm{G}}$ (danger of a high impulse current between the capacitor battery and the capacitor in the DC bus).
To avoid this risk, the input current of the VS inverter has to be additionally dependent on the $\mathrm{DC}$ voltage.

The capacity of the capacitors $\mathrm{C}_{\mathrm{A}}, \mathrm{C}_{\mathrm{B}}, \mathrm{C}_{\mathrm{C}}$ should be determined due to the possibility of the generator selfexcitation. The largest capacity is required at the lowest assumed angular velocity at which the generator can still operate correctly. It is known, that the higher the angular velocity is, the smaller can be the battery capacity. The required capacity is determined by the intersection of the nonlinear characteristic of the voltage induced in the generator with a linear characteristic representing the dependence of the capacitor voltage on its current (Fig. 5). It should be emphasized that the normal operation of the SCI generator takes place below the intersection point of these characteristics. Assuming that the voltage in the DC bus can vary within a certain range, the scope of the normal generator operation is shown in Figure 5 as the highlighted area.

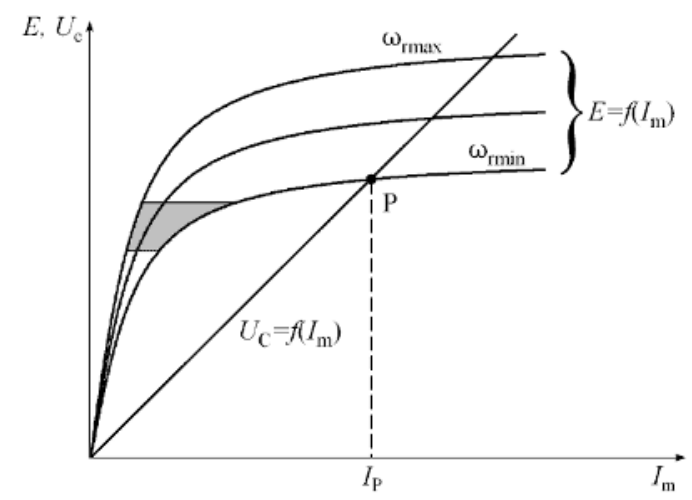

Figure 5. Dependences of the voltage $E$ induced in the generator and the voltage $U_{\mathrm{C}}$ of the capacitor battery on the magnetizing current $I_{\mathrm{m}}: \mathrm{P}-$ point of the generator stable operation after its self-excitation.

The self-excitation process should take place in an unloaded state. So, we can assume with a certain approximation that the magnetizing and capacitor currents are equal to each other. On the basis of this condition, we can write the following relationship for the intersection point of the above mentioned characteristics (point $\mathrm{P}$ in Figure 5):

$$
\psi\left(I_{\mathrm{m}}\right) \omega_{\text {rmin }}=\frac{1}{2 \pi f_{\mathrm{G}} C} I_{\mathrm{P}}
$$

where: $\psi\left(I_{\mathrm{m}}\right)$ - magnetic flux, $\omega_{\mathrm{rmin}}$ - assumed minimum value of the generator angular velocity, $f_{\mathrm{G}}-$ frequency of the generator current, $C$ - required capacity, $I_{\mathrm{P}}-$ magnetizing current of the SCI generator for the point $\mathrm{P}$, Hence, the capacity should fulfil the condition:

$$
C \geq \frac{I_{\mathrm{m}}}{2 \pi f_{\mathrm{G}} \psi\left(I_{\mathrm{m}}\right) \omega_{\mathrm{rmin}}}
$$

The capacitor in the DC bus is selected due to the VS inverter operation. However, voltage fluctuations on this capacitor depend also on the operation of the generator and capacitor battery. The largest increase in DC voltage occurs when the capacitor battery is permanently disconnected from the generator. In this case the almost 
total magnetic energy associated with the leakage inductances of the generator stator is transferred to the DC capacitor. Hence, it can be written:

$$
\frac{3}{4} L_{\mathrm{s} \sigma} I_{\mathrm{Gmax}}^{2}=\frac{1}{2} C_{\mathrm{DC}}\left(U_{\mathrm{DCmax}}^{2}-U_{\mathrm{DCmin}}^{2}\right)
$$

where: $L_{\mathrm{s} \sigma}-$ leakage inductance of the generator stator, $I_{\mathrm{Gmax}}$ - maximum amplitude of the generator current, $U_{\text {Dcmax }}, U_{\text {Dcmin }}-$ admissible maximum and minimum values of the DC voltage, respectively.

So, the capacity should be equal to:

$$
C_{\mathrm{DC}}=\frac{\frac{3}{2} L_{\sigma \mathrm{s}} I_{\mathrm{Gmax}}^{2}}{U_{\mathrm{DC} \max }^{2}-U_{\mathrm{DC} \min }^{2}}
$$

It is necessary but insufficient condition referring to the DC capacitor because its final selection depends on the assumed operation parameters of the VS inverter.

The main principle of the control method is to maintain a constant voltage in the DC bus; in practice, this voltage can vary within a relatively narrow range. The control system generates a control signal, as the PI controller output signal, which is compared with the saw-tooth signal of a frequency of several $\mathrm{kHz}$ (Fig. 6). When the voltage induced in the generator should increase (it requires an increase in the magnetic flux), then the value of this control signal has to be appropriately higher. As a result, the time interval in which the capacitor battery is connected to the generator is longer. In time interval $t_{1}-t_{2}$ the switches $\mathrm{S}_{\mathrm{G}}$ are turned on and the capacitor battery is connected to the generator, while in the interval $t_{2}-t_{3}$ these switches are turned off.

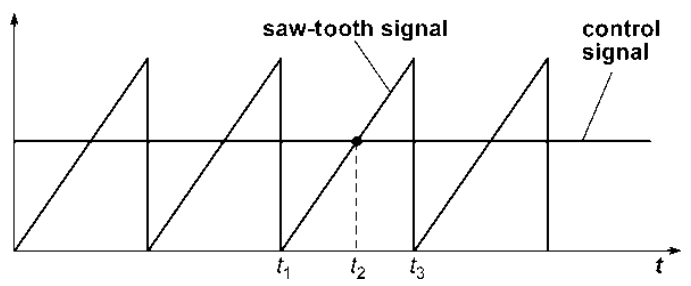

Figure 6. Principle of the capacitor battery switching.

\section{Numerical calculations of proposed system operation \\ of the}

A monoharmonic model of the squirrel cage induction machine was used in numerical analysis of the proposed system operation [21]. It was assumed that the magnetization characteristic is nonlinear but unambiguous. Numerical tests were carried out for the generator with the nominal parameters: power $-22 \mathrm{~kW}$, phase-to-phase voltage $-400 \mathrm{~V}$, angular velocity $1470 \mathrm{rpm}$, current - $41 \mathrm{~A}$. For this generator, parameters of its equivalent circuit were following: resistivity of the stator windings - $0.241 \Omega$, leakage inductance $1.864 \mathrm{mH}$, magnetizing inductance $-27.8 \mathrm{mH}$.

The process of the self-excitation is shown in Figure 7 (the angular velocity is equal to $1500 \mathrm{rpm}$ ). The capacity required to the generator self-excitation is equal to $0.32 \mathrm{mF}$. This process does not last to the point $\mathrm{P}$ in
Figure 5 because the capacitor battery is disconnected when the generator magnetic flux reaches the required value resulting from the assumed DC voltage and current angular velocity. From this moment the normal operation of the proposed energy generation system begins.

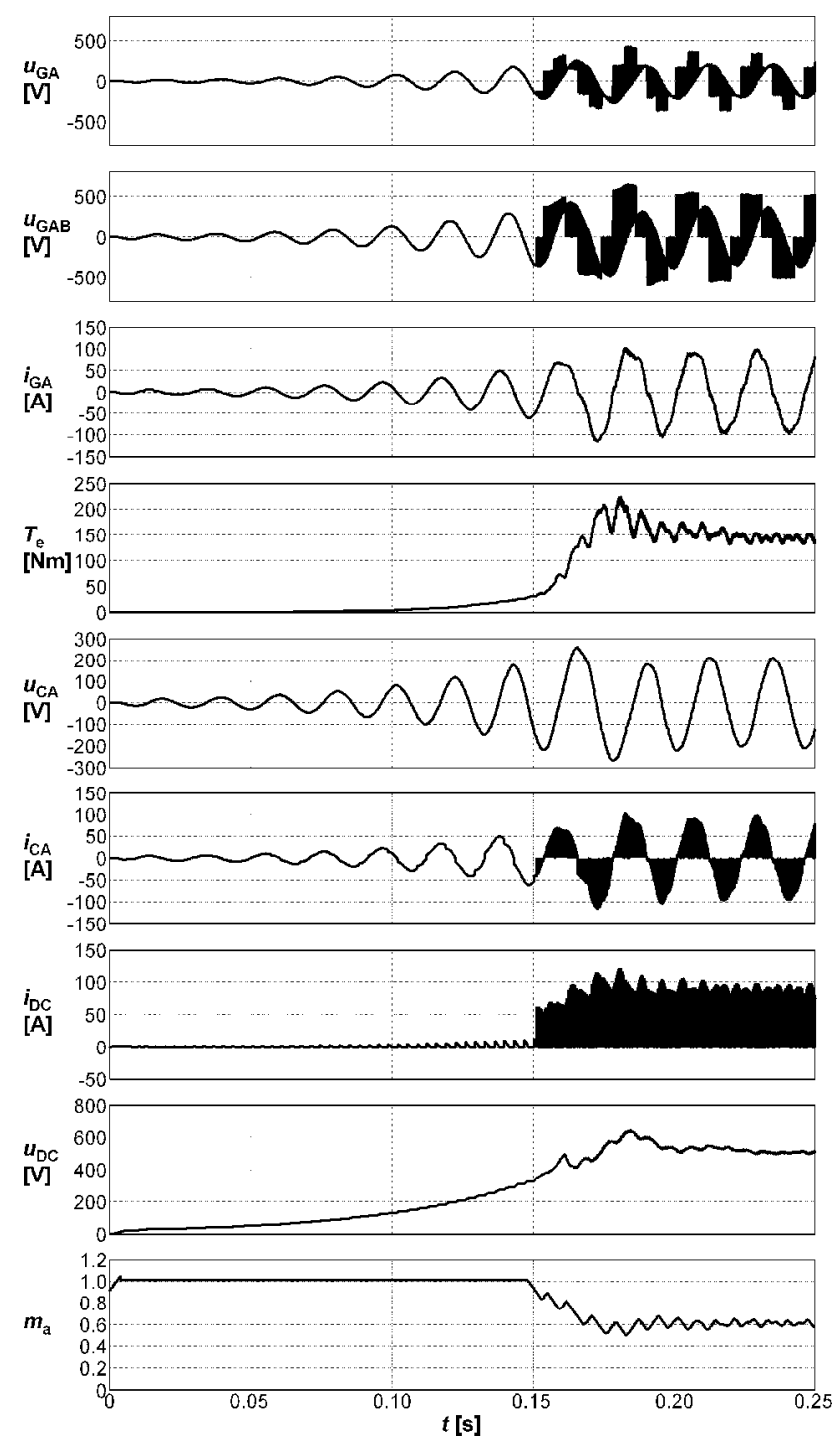

Figure 7. Waveforms of voltages, currents and the generator torque in the proposed energy generation system during the selfexcitation process: $U_{\mathrm{DC}}=500 \mathrm{~V}, \omega_{\mathrm{r}}=1500 \mathrm{rpm}, C_{\mathrm{G}}=1.0 \mathrm{mF}$, $C_{\mathrm{DC}}=0.5 \mathrm{mF}, f_{\mathrm{s}}=3 \mathrm{kHz} ; u_{\mathrm{GA}}, u_{\mathrm{GAB}}-$ phase and phase-to-phase generator voltages, respectively, $i_{\mathrm{GA}}-$ generator current, $T_{\mathrm{e}}-$ generator torque, $u_{\mathrm{CA}}, i_{\mathrm{CA}}-$ voltage and current of the capacitor battery, respectively, $i_{\mathrm{DC}}, u_{\mathrm{DC}}-$ current and voltage in the DC bus, respectively, $m_{\mathrm{a}}$ - ratio of turn-on time of the switches $\mathrm{S}_{\mathrm{G}}$ to the switching period.

Figure 8 presents waveforms of chosen voltage and currents and changes of the generator torque during normal operation with the following conditions: $U_{\mathrm{DC}}=$ $500 \mathrm{~V}, \omega_{\mathrm{r}}=1500 \mathrm{rpm}, C_{\mathrm{G}}=1.0 \mathrm{mF}, C_{\mathrm{DC}}=0.5 \mathrm{mF}, f_{\mathrm{s}}=$ $3 \mathrm{kHz}$. In turn, Figure 9 presents analogous waveforms for the minimum value of the generator angular velocity which was assumed as $750 \mathrm{rpm}$. In this case the number of switching processes is two times higher than before. It should be noted that the smaller the generator velocity is, the higher is the content of higher harmonics in the generator current. Consequently, the variable component 


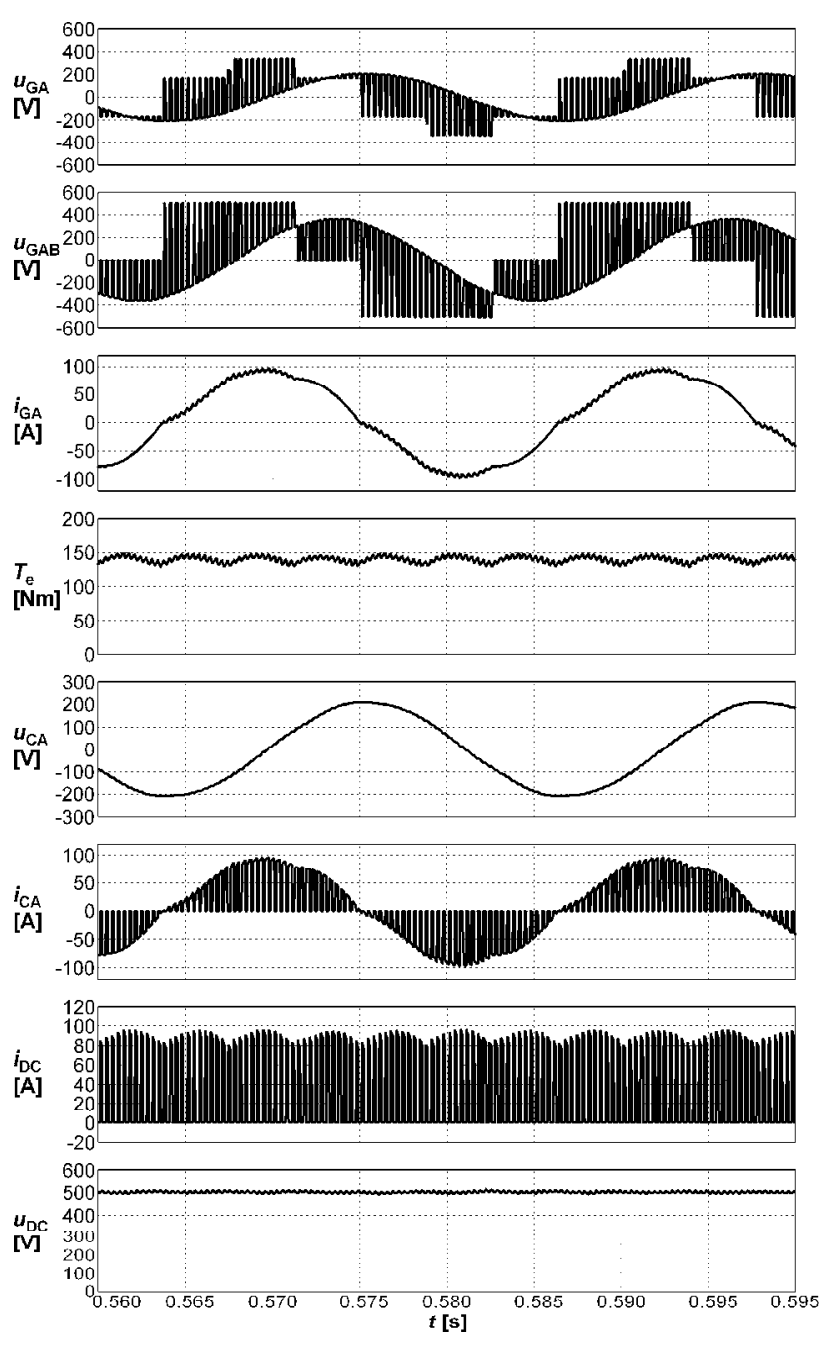

Figure 8. Waveforms in the proposed energy generation system for $\omega_{\mathrm{r}}=1500 \mathrm{rpm}$; descriptions of waveforms as in Fig. 7 .

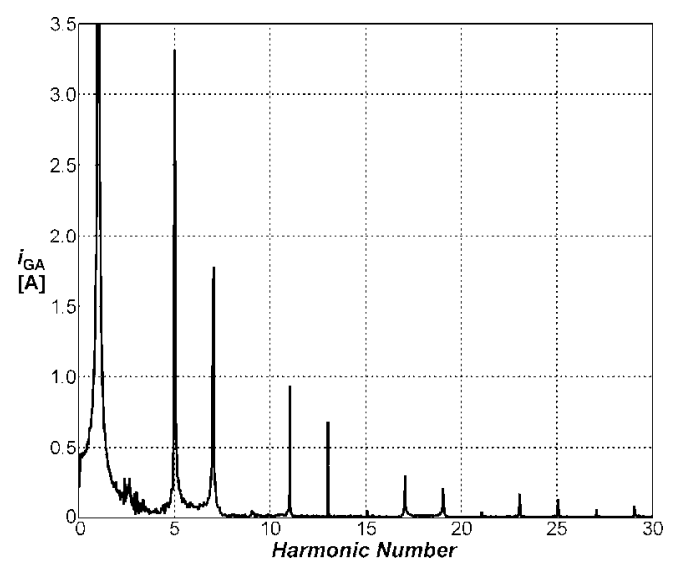

Figure 10. Harmonic spectrum of the generator current presented in Figure 8; amplitude of the first harmonic is equal to $60 \mathrm{~A}$.

of the generator torque is higher; it negatively influences the torque transfer system. Figures 10 and 11 show harmonic spectra of the generator currents presented in Figure 8 and Figure 9 respectively. The fifth and seventh harmonics are significant higher harmonics in both cases. However, in the first case $(1500 \mathrm{rpm})$ the amplitudes of these harmonics are respectively around $10 \%$ and $5 \%$ with respect to the amplitude of the basic

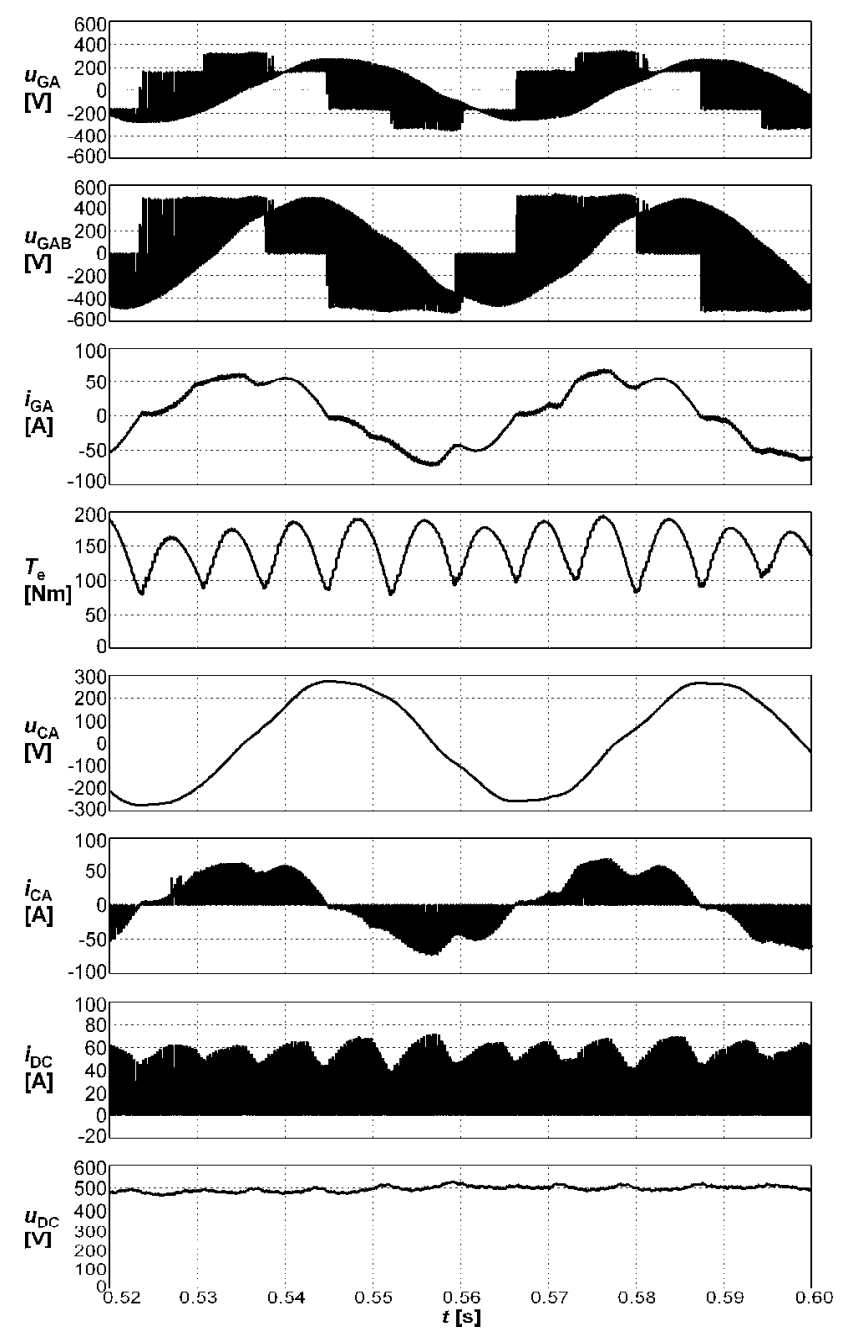

Figure 9. Waveforms of voltages, currents and the generator torque in the proposed energy generation system: $\omega_{\mathrm{r}}=750 \mathrm{rpm}$; descriptions of waveforms as in Fig. 7.

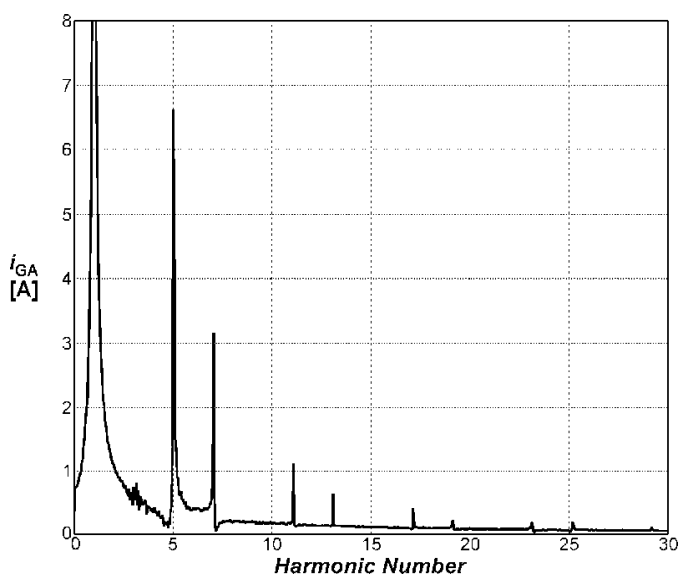

Figure 11. Harmonic spectrum of the generator current presented in Figure 9; amplitude of the first harmonic is equal to $40 \mathrm{~A}$.

harmonic; in the second case $(750 \mathrm{rpm})$ these amplitudes are higher than previously and they are approximately $16 \%$ and $8 \%$. This leads to an increase in the variable component of the generator torque, which is undesirable.

The content of higher harmonics in the generator current depends on its load; analytical description of this dependence is currently a subject of further studies, 
which allow us to take into account different parameters of the induction generator.

\section{Conclusions}

In this paper the novel concept of the energy generation system with the use of the squirrel cage induction generator is presented. Numerical calculation results allow us to state that the proposed energy generation system operates correctly for the assumed conditions, especially for different values of the generator angular velocity.

This system can be treated as an alternative to existing solutions which use the cage induction generators and the back-to-back converter. This proposal has several advantages in comparison to existing systems. The control method is simpler because the switches are turned on or turned off at the same time by one common signal. Moreover, the capacitor battery can be switched on by means of only two Insulated Gate Bipolar Transistors.

The proposed energy generation system can operate at various generator angular velocities. It is significant in the cases when the speed of the wind or the water stream varies within a wide range. In order to convert the total energy provided by the wind or the water stream into the electrical energy, the mechanical characteristics of the given turbine should be taken into the control method.

It should be notified that the validation of the correctness of the proposed energy generation system requires comprehensive research with the use of a laboratory stand. This system is especially dedicated to small wind and water plants. It is necessary to stress that the proposed method of energy generation can also be used in autonomous operation systems (island systems). However, in this case the control method of the output voltage source inverter should be modified due to the lack of the external grid.

\section{References}

1. M. Cheng, Y. Zhu., Energy Conv. and Manag., 88, 332-347 (2014)

2. F. Blaabjerg, Z. Chen, R. Teodorescu, F. Iov, 5th International Conference Power Electronics and Motion Control, 1, 1-11 (2006)
3. A. Sikorski, A. Kuźma, Bulletin of the Polish Ac of Sc., Tech. Sc., 57, No. 4, 317-322 (2009)

4. F. Blaabjerg, F. lov, R. Teodorescu, Z. Chen, 12th International Conference Power Electronics and Motion Control EPE-PEMC, 1-17 (2006)

5. A.R. Tiwari, A.J. Shewale, A.R. Gagangras, N.M. Lokhande, Multidisciplinary Jour. of Research in Eng. and Techn., 1, Iss. 2, 129-135 (2014)

6. M. G. Simões, S. Chakraborty, R. Wood, Third Quart. IEEE Power Electr. Soc. News., 19, 19-23 (2006)

7. G. Quinonez-Varela, A. Cruden, IET Gener. Transm. Distrib., 2, (2), 301-309 (2008)

8. F. Blaabjerg, Z. Chen, S.B. Kjaer, IEEE Trans. on Power Electr., 19, No. 5, 1184- 1194 (2004)

9. J.A. Baroudi, V. Dinavahi, A.M. Knight, Ren. Energy, 32, 2369-2385 (2007)

10.J.G. Trapp, F.A. Farret, F.T. Fernandes, L.C. Corrêa, 10th International Conference on Industry Applications (INDUSCON),1-8 (2012)

11. M. Molinas, B. Naess, W. Gullvik, T. Undeland, European Conference on Power Electronics and Applications EPE, 1-10 (2005)

12. A.B. Lehru, D. Chirag, K. Vibhakar, Int. Jour. of Eng. Research and Develop., April, 6-13 (2015)

13. R. Cárdenas, R. Peña, IEEE Trans. on Energy Conv., 19, No. 1, 196-205 (2004)

14. R. Peña, R. Cardenas, R. Blasco, G. Asher, J. Clare, 27th Annual Conference of the IEEE Industrial Electronics Society (IECONO1), 1376-1381 (2001)

15.E.J. Bueno, S. Cóbreces, F.J. Rodríguez, Á. Hernández, F. Espinosa, IEEE Trans. on Energy Conv., 23, No. 3, 932-945 (2008)

16. A. Binder, T. Schneider, 11th European Conference on Power Electronics and Applications, P10 (2005)

17. A.M. El-Refaie, T.M. Jahns, 27, Is. 5, 967-984(2008)

18. W. Mazgaj, Z. Szular, T. Węgiel, T. Sobczyk, Przeg. Elektrot. 5, 282-287 (2011)

19. T.J. Sobczyk, W. Mazgaj, Z. Szular, T. Węgiel, Arch. of Elec. Eng., 60, No 2, 159-168 (2011)

20.D. Borkowski, T. Węgiel, IEEE Trans. on Energy Conv., 28, No 2, $452-459$ (2013)

21.Z. Szular, Techn. Trans., Elec. Eng., 2-E, 149-158 (2015) 